\title{
In memoriam Giorgio Pilleri (1925-2018)
}

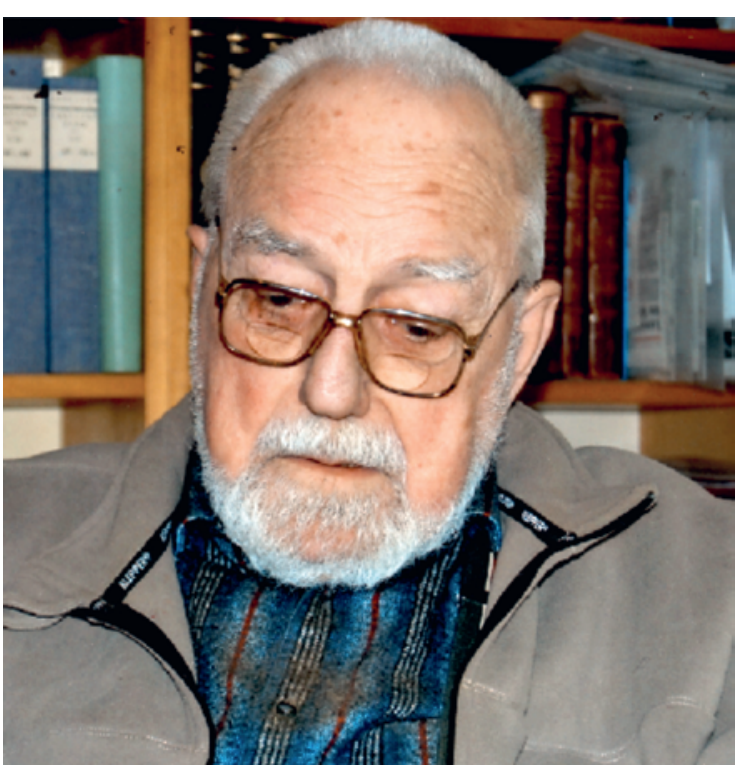

Prof. Dr. med. em. Giorgio Pilleri

\section{Ein Naturforscher von altem Schrot und Korn}

Prof. em. Giorgio Pilleri, von 1965 bis 1990 Direktor des Hirnanatomischen Instituts der Psychiatrischen Universitätsklinik Bern, ist am 4. September 2018 im Alter von 93 Jahren in Courgevaux bei Murten gestorben.

Mit Giorgio Pilleri hat uns ein in vieler Hinsicht ausserordentlicher Mensch verlassen: ein ungeheuer vielseitig interessierter Arzt und Neuropathologe, ein umfassender Naturforscher von altem Schrot und Korn, ein Sammler und Publizist weit über seine engen Fachgrenzen hinaus. Dazu ein scharfsinniger Menschenbeobachter und begnadeter Erzähler mit einem goldenen und - wie u.a. in seinen autobiographischen Plaudereien aus der medizinischen Schule (Berlin, 2010) - manchmal auch recht bissigen Humor.

\section{Von Triest nach Bern}

Giorgio Pilleri stammte aus Triest. Schon früh interessierte er sich leidenschaftlich für Naturwissenschaft und Biologie. Bereits als Jugendlicher legte er eine riesige Käfersammlung an, die noch heute im naturhisto- rischen Museum von Verona zu sehen ist. Während des Krieges arbeitete er im naturhistorischen Museum von Triest als wissenschaftlicher Illustrator und Bibliothekar. Anschliessend studierte er zuerst in Padua, dann in Wien und schliesslich in Bern Medizin. Schon als Student famulierte er mehrfach im Berner Hirnanatomischen Institut unter Professor Ernst Grünthal, dessen Assistent er 1957 und dessen Nachfolger er 1965 wurde. 1962 erhielt er in Bern die Venia legendi, und 1970 wurde er zum nebenamtlichen ausserordentlichen Professor für Neuroanatomie und vergleichende Neuropathologie mit Lehrauftrag in beiden Fächern ernannt.

\section{Expeditionen und Publikationen}

Ausgehend von seiner Tätigkeit als Prosektor und Hirnanatom an der Psychiatrischen Universitätsklinik Waldau entfaltete er eine reiche Forschungstätigkeit, die ihn weit über die menschliche Neuropathologie in die vergleichende Anatomie und Verhaltensforschung u.a. von Delfinen, Walen und Bibern hineinführte. Das Material zu seinen Untersuchungen beschaffte er sich auf insgesamt 18 oft recht abenteuerlichen wissen-

Ein scharfsinniger Menschenbeobachter und begnadeter Erzähler mit einem goldenen und manchmal auch recht bissigen Humor.

schaftlichen Expeditionen nach Nord- und Südamerika, Südafrika, Indien und China. Die Frucht waren über 600 (!) wissenschaftliche Publikationen, darunter mehrere Bücher, Reiseberichte und Monographien. Pilleri war zudem Herausgeber von drei wissenschaftlichen Zeitschriften (Brain and Pathology; Investigations on Cetacea - 25 Bände; Investigations on Beavers -

Ihm gelang der Nachweis eines umgekehrt zur Entwicklung des kindlichen Gehirns ablaufenden Hirnabbaus beim Morbus Alzheimer.

7 Bände), Mitglied verschiedener wissenschaftlicher Fachgesellschaften sowie Beirat von mehreren wissenschaftlichen Zeitschriften und erhielt für seine Leistungen eine Reihe von internationalen Auszeichnungen. Zu seinen wichtigsten Entdeckungen gehört der Nachweis eines umgekehrt zur Entwicklung des kindlichen Gehirns ablaufenden Hirnabbaus beim Morbus 
Alzheimer. Bemerkenswert sind im gleichen Zusammenhang auch seine Untersuchungen zum Phänomen des pathologischen Lachens und Weinens. Besonders interessierte sich Pilleri ausserdem für den Nucleus basalis von Meynert (NBM), zu jener Zeit noch eine ausgesprochene obscura textura des Zentralnervensystems. Durch vergleichende Studien fand er heraus, dass die Entfaltung dieser subkortikalen Formation mit der fortschreitenden Zerebralisation in der Evolution zusammenhängt und damit einen phylogenetischen Neuerwerb darstellt. Mensch und Delphin weisen die grössten NBM auf. Beim Morbus Alzheimer stellt der NBM den ersten Angriffspunkt der Noxe dar, und seine Atrophie geht derjenigen der Grosshirnrinde voraus. Von erheblichem Allgemeininteresse ist ebenfalls der durch Pilleri erbrachte Beweis, dass die Cetaceen, obwohl phylogenetisch und ökologisch von den Primaten völlig getrennt, in mancher Hinsicht einen dem Homo sapiens vergleichbaren und zum Teil sogar überlegenen Entwicklungsstand erreicht haben.

\section{Seine letzten Jahre}

Nach seiner Emeritierung 1990 lebte Giorgio Pilleri mit seiner Frau Rosa, einer gebürtigen Emmentalerin, während einiger Jahre in Paciano am Lago Trasimeno in Italien, wo er seine wissenschaftlichen und publizis- tischen Arbeiten weiterführte. Nach seiner Rückkehr in die Schweiz (2007) wohnte er in Courgevaux im Kanton Freiburg. 1991 erhielt er das Schweizer Bürgerrecht in Heimiswil. Seine letzten Jahre waren von zunehmenden körperlichen Beschwerden und chronischen Schmerzen überschattet, die er mit Humor zu ertragen und, dank seinem bis zuletzt stupenden Gedächtnis,

Er überraschte seine Freunde immer wieder mit wunderbar poetischen aus gepressten Blumen, Blättern und Gräsern gefertigten Karten.

mit der Abfassung von meisterhaften, zum Teil in italienischer oder slowenischer Sprache veröffentlichten Erinnerungsvignetten aus seinem reichen Leben $\mathrm{zu}$ vertreiben suchte. Noch in seinen letzten Jahren überraschte er seine Freunde auch immer wieder mit wunderbar poetischen aus gepressten Blumen, Blättern und Gräsern gefertigten Karten. Für alle, die ihn persönlich gekannt haben, war Giorgio Pilleri ein einmalig origineller und in Dingen, die ihm - wie Natur und Naturschutz - besonders am Herzen lagen, auch ausgesprochen kämpferischer, vor allem aber: ein sehr liebenswerter Mensch.

Prof. Dr. med. em. Dr. h.c. Luc Ciompi Belmont-sur-Lausanne 